\title{
Comment
}

\section{Rejoinder to Daniel Everett}

N.J. Enfield Max Planck Institute for Psycholinguistics

My piece (Enfield 2013) wasn't a review but a commentary on what I'm reading, using Everett's book in the light of related work to articulate three fundamental questions in the anthropology of language today. The author is unhappy, but it's no good berating a commentator for representing his own view, or trying to discredit a critic by asserting that he's ignorant. Nor does it make sense to suggest that I might be unaware of the actuation problem when an entire section of my essay was devoted to it. The issue of the causal anatomy of cultural diffusion - as reviewed, for example, in Rogers' monumental Diffusion of innovations (2003) - is as close to settled as anything we have.

\section{REFERENCES}

ENFIELD, N.J. 2013. Language, culture, and mind: trends and standards in the latest pendulum swing. Daniel Everett, Language: the cultural tool. London: Profile, 2012 [What I'm reading]. Journal of the Royal Anthropological Institute (N.S.) 19, 155-69.

Rogers, E.M. 2003. Diffusion of innovations (Fifth edition). New York: Free Press.

N.J. Enfield is Professor of Ethnolinguistics at Radboud University and is a senior staff scientist at the Max Planck Institute, Nijmegen, The Netherlands. He is leader of the European Research Council project 'Human Sociality and Systems of Language Use' (2010-14). His recent books include (as editor) Dynamics of human diversity (Pacific Linguistics, 2011) and (as author) Relationship thinking: agency, enchrony, and human sociality (Oxford University Press, 2013).

Max Planck Institute for Psycholinguistics, PO Box 310, 6500 AH Nijmegen, The Netherlands. Nick.Enfield@ mpi.nl 